\title{
APPLICATION OF ISO22000 AND FAILURE MODE AND EFFECT ANALYSIS (FMEA) FOR INDUSTRIAL PROCESSING OF POULTRY PRODUCTS
}

\author{
Theodoros H. Varzakas ${ }^{1, *}$, Ioannis S. Arvanitoyannis ${ }^{2}$ \\ 1 Technological Educational Institute of Kalamata, School of Agricultural Sciences, \\ Department of Agricultural Products Technology, Hellas (Greece) E-mail: theovarzakas \\ (a)yahoo.gr \\ *Whom all correspondence should be addressed to \\ ${ }^{2}$ University of Thessaly, School of Agricultural Sciences, Department of Agriculture, Animal \\ Production and Aquatic Environment, Fytoko Street, 38446 Nea Ionia Magnesias, Volos, \\ Hellas (Greece)
}

Abstract: $\quad$ Failure Mode and Effect Analysis (FMEA) model has been applied for the risk assessment of poultry slaughtering and manufacturing. In this work comparison of ISO22000 analysis with HACCP is carried out over poultry slaughtering, processing and packaging. Critical Control points and Prerequisite programs (PrPs) have been identified and implemented in the cause and effect diagram (also known as Ishikawa, tree diagram and fishbone diagram).

However, the main emphasis was put on the quantification of risk assessment by determining the RPN per identified processing hazard. Evisceration, reprocessing, immersion chilling and cooling/freezing/ distribution were the processes identified as the ones with the highest RPN $(324,252,240,210$, respectively) and corrective actions were undertaken. Following the application of corrective actions, a second calculation of RPN values was carried out leading to considerably lower values (below the upper acceptable limit of 130). It is noteworthy that the application of Ishikawa (Cause and Effect or Tree diagram) led to converging results thus corroborating the validity of conclusions derived from risk assessment and FMEA. Quantification of risk assessment was also carried out for a sliced poultry sandwich and for refrigerated chicken salad. RPN was determined before and after corrective actions. Therefore, the incorporation of FMEA analysis within the ISO22000 system of a poultry processing industry is considered imperative.

Please use the following format when citing this chapter:

Varzakas, T.H. and Arvanitoyannis, I.S., 2009, in IFIP International Federation for Information Processing, Volume 295, Computer and Computing Technologies in Agriculture II, Volume 3, eds. D. Li, Z. Chunjiang, (Boston: Springer), pp. 1783-1795. 
Keywords: FMEA; ISO22000; HACCP; Ishikawa diagrams; Poultry manufacturing.

\section{INTRODUCTION}

The L. monocytogenes surveillance programme has shown an increase in the incidence of this micro-organism in meat products, especially poultry (unpublished data). It is thus possible that some of the sporadic cases of listeriosis observed in Italy for which the vehicle of infection was not identified may have been associated with the consumption of foods of animal origin.

Sumner et al. (2004) reported that their study had parallels with the findings of Schlosser et al. (2000) and Sarwari et al. (2001). Firstly, there was no great concurrence between the suite of serovars isolated most frequently from red meat and those most commonly associated with salmonellosis in Australia. Secondly, S. sofia was isolated from $50 \%$ of poultry samples and yet caused only $0.3 \%$ of salmonelloses, pointing to a very low ability to cause human illness.

In the case of poultry meat, however, phage types of S. typhimurium isolated from poultry were responsible for a significant proportion of salmonelloses, a situation which pertained both before and after regulatory change.

Poultry carcasses usually have very high levels of contamination on the skin. They can present microorganisms that cause food-born illness as well as food spoilage. There are a series of microorganisms on the surface of the carcasses which can be analyzed in order to indicate the microbiological quality, the level of hygiene in production and handling, and the correct maintenance of the cold chain (Sandrou and Arvanitoyannis, 1999). Furthermore, they can help to predict products' shelf-life. The flow diagram of slaughter and dressing of chicken broilers is given in Figure 1.

Three mechanisms exist for the attachment of bacteria on poultry carcasses (NACMSF, 1997). Retention occurs when carcasses come into contact with water containing bacteria. Entrapment occurs when exposed tissue surfaces (skin, collagenous connective tissue layers of muscle) absorb water and begin to swell. Adhesion occurs when microorganisms adhere to surface tissues. Only some strains of salmonellae are capable of adhesion. It looks certain that bacteria are firmly attached to carcasses before the start of processing and hence it is very difficult to get eliminated in the processing premises.

Stunning and bleeding: After leaving the holding areas, the animals are located in a stunning or immobilization area where they are rendered unconscious. Cattle stunning in the United States are usually done by a bolt 
pistol or electric shock. The anesthetized animals are then shackled and hoisted (hind quarters up) onto a overhead rail or dressing trolley. Bleeding (exsanguination) or sticking is conducted with the blood collected in a trough or floor drain for disposal or further processing.

Scalding is a process by which the bird is subjected to moist heat for a short time to loosen hair and facilitate the removal of feathers. Immersion scalding using a single or two-stage scalder usually occurs in New Zealand. Soft scalds $\left(<=55^{\circ} \mathrm{C}\right)$ and hard scalds $\left(>55^{\circ} \mathrm{C}\right)$ are being used for up to 3 minutes. When birds are immersed in the scalding tank, some of the dirt, faecal material and other contaminants on the surface of the bird are removed and contaminate the scald water, hence scalding could be a means of cross-contamination.

The number and incidence of Salmonella and Campylobacter in raw poultry carcass are greatly affected by the operating conditions of scalding and defeathering, evisceration, washing, skinning, boning, portioning, chilling, decontaminating (irradiation) and freezing. In commercial scalding, temperature is set in a range of 50 to $60^{\circ} \mathrm{C}$ for 2 to $2.5 \mathrm{~min}$. One study found that increasing of scalding water temperature from 50 to $60^{\circ} \mathrm{C}$ reduced the number of C. jejuni and S. Typhimurium by approximately $6 \log \mathrm{CFU} / \mathrm{ml}$ (Yang et al., 2001). In contrast, Humphrey (2004) found that hot water (up to $80^{\circ} \mathrm{C}$ ) treatments were not much more effective in removing campylobacters as compared to cold water. So, he suggested that heat treatment is not a significant control measure, particularly when chicken carcasses are to be sold whole.

Treatment of wash water has been found to be a potential processing control to reduce contamination. Alternatives are treatment with chlorine water, electrolyzed water, trisodium phosphate, cetylpyridinum chloride, hydrogen peroxide etc.

The main objection to immersion scalding is the possible inspiration of contaminated scald water by the birds, with subsequent contamination of air sacs, lungs and other internal organs and edible tissues by pathogenic bacteria (Bailey et al. 1987). Hard scalding at about $58-60^{\circ} \mathrm{C}$, followed by mechanical plucking, results in removal of the outer epidermal layer of the bird's skin. This cuticle-free skin of hard-scalded broilers serves as a more suitable substrate for bacterial attachment (Kim et al., 1993).

Counter-current scalders and multi-stage scalders have a greater impact on reducing the level of microorganisms on the carcass (Bolder, 1998). Multitank also reduce both the total aerobic and enterobacterial counts (Stals, 1996).

Defeathering is considered as a major site of cross-contamination for poultry carcasses by pathogens such as Camplylobacter and Salmonella and E. coli. (NACMCF, 1997). 
During the process, feathers, dirt and bacteria from carcasses are removed, however, creation of aerosols is being carried out that spread bacteria, water and solid matter, contaminating other carcasses (Tinker et al., 1996). Staphylococcus aureus might also colonise the machinery by getting associated with the rubber fingers used to remove the feathers. Despite all these bacteria and their possible presence, defeathering can result in a reduction on carcass contamination by 1000 -fold as reported by Hinton et al. (1996). Cross-contamination could be reduced if defeathering took place on a carousel.

Dressing and hide removal: The bled carcasses are conveyed to the slaughter area where dressing (cleaning) and evisceration occurs. Dressing is carried out from the overhead position or by placing the carcass in a cradle. The skin is removed from the head and the head separated from the body. The fore and hind feet are then removed to prevent contamination of the carcass with manure and dirt dropped from the hooves (shanking or legging). Each leg is then skinned. The remaining hide is removed from the carcass with electric or air-powered rotary skinning knives. The hides are preserved by salting or chilling on ice before being sent to a tannery for processing into leather

(http://wrrc.p2pays.org/p2rx/subsection.cfm?hub=449andsubsec $=11$ andnav $=$ 1 andCFID=1245734andCFTOKEN=43813664).

Evisceration can be a major source of faecal contamination on carcasses and edible offal, particularly if the intestines are cut or broken. This will result in an increase in contamination by mesophilic bacteria including pathogens such as Salmonella, Campylobacter, Clostridium perfringens, and Listeria.

New Zealand uses small processing premises whereas large premises use autmoamtic equipment (MAF, 2000).

The skinned carcasses are opened to remove the viscera (internal body organs). The abdomen is opened from the top to bottom where the internal organs are loosened and removed from the body. The abdominal organs are inspected and the stomach and intestine are emptied of manure and cleaned for further processing. A handsaw is used to halve the remaining carcass by cutting through the center of the backbone. The inedible materials are collected and sent to a rendering plant for manufacture of feed materials. The beef sides are washed to remove any remaining blood or bone dust and the carcasses are physically or chemically decontaminated. The simplest physical decontamination method involves spraying with high pressure water or steam. Chemical decontaminants include acetic and lactic acids, and aqueous solutions of chlorine, hydrogen peroxide and inorganic acids.

Operator skills influence the levels of gut breakage in smaller plants. Moreover, full crops and intestinal tracts increase the risk of gut breakage, hence feed should be withdrawn carefully prior to processing (Izat et al., 
1989). In addition, shorter withdrawal periods may have more advantages in the reduction of bacteria in the crop and the caeca.

Finally, spray cleaning of carcasses during evisceration could prevent the occurrence of Salmonella and Enterobacteriaceae. Moreover, rinsing with chlorinated water could aid the minimization of cross-contamination.

Proper cleaning and effective sanitation is an essential component of processing poultry, as it contributes significantly to the prevention of product contamination with microorganisms that cause food-borne disease and spoilage. Rapid expansion of production volume, increased furtherprocessing and introduction of diverse ready-to-cook and ready-to-eat products, sophistication of the processing equipment, implementation of HACCP and microbial finished-product standards, and, more importantly, expensive product recalls have necessitated greater control over the cleaning and sanitation process.

The main emphasis of HACCP in slaughter operations is to minimise the potential for contamination of the finished raw products (Untermann, 1993). Current technology cannot assure a pathogen-free product (Baumgart, 1993), but it can minimise contamination from any slaughter operation (Goodfellow, 1995). Two fundamental concepts must be considered during the slaughtering process. The first one is related to the use of procedures which will minimise the degree of contamination on carcasses, such as training workers, providing adequate work space and time, providing a plant layout that flavours microbial control, and selecting equipment. For this purpose, cost-effective technology is needed (Mackey and Roberts, 1993). The second concept is to include procedures which can reduce or destroy pathogens which inadvertently contaminate the carcass during slaughtering (Tompkin, 1994).

Immersion chilling (immersion in ice or chilled water) or a combination of immersion chilling and wet air chilling (blast air chillers) are the methods used to reach an internal carcass temperature of $4^{\circ} \mathrm{C}$ within 24 hours of dressing. It takes approximately 50 minutes to achieve this temperature and the use of chlorinated water is essential. However, immersion chilling is an area of cross-contamination with C. jejuni, Salmonella and Clostridium perfringens (Lillard, 1990). Chlorine can facilitate the hygienic operation of these systems. Chlorine dioxide could also be added to reduce Salmonella in chiller water.

Four hazards are likely to occur: physical contamination with fecal material and potential pathogen contamination at evisceration/presentation, pathogen contamination at reprocessing, pathogen cross-contamination and proliferation at chilling, and pathogen proliferation at finished products storage (cold). Four CCPs address these four hazards: proper evisceration/presentation, proper reprocessing, and proper chilling of product and proper maintenance of finished product temperatures during storage 
(Table 1, 2). The ISO 22000 Analysis worksheet for the determination of prerequisite programs for poultry slaughtering and synoptical presentation of HACCP plan are given in Table 1 and Table 2, respectively. Moreover in Fig.1 the main processing stages of poultry slaughtering are presented.

\section{RESULTS OF FAILURE MODE AND EFFECTS ANALYSIS}

In FMEA analysis, risk of contamination and its presence at Hazardous Fraction in the final product, is expressed with the risk Priority Number (RPN) which is defined as follows:

$$
\mathrm{RPN}=\mathrm{S} \times \mathrm{O} \times \mathrm{D}
$$

Where S: Severity of contamination risk, O: supply probability occurrence of contaminated ingredient, D: Detection probability of contaminated ingredient.

FMEA tables were constructed where Hazardous Elements (ingredients) are assessed and RPN was calculated as can be seen in Table 3.

The classification of hazardous elements occurs according to the RPN assessment as can be seen in Table 5 and corrective actions are proposed per identified hazard. The new RPN is calculated following undertaking of corrective actions.

The limit for RPN is 130 and if this number exceeds 130 corrective action should be implemented.

Ishikawa or Fishbone diagrams analyse all the dangers at all processing stages where CCPs are incorporated. These diagrams consist of five basic axes: man, machine, materials, methods and environment. In these axes the danger is described. Only one diagram is presented here and that refers to the cooling, storage and distribution of poultry processing.

In Figure 2 the Ishikawa is applied to detect the causes that might be due to the physical, chemical and microbiological dangers occurring at the storage and distribution stages. Regarding man the main problem is bad distribution due to the inadequate training of workers. Regarding machines the problem might be due to the wrong placement of packaging, or the bad adjustment of the temperature of the transportation vehicle due to inadequate personnel training. 


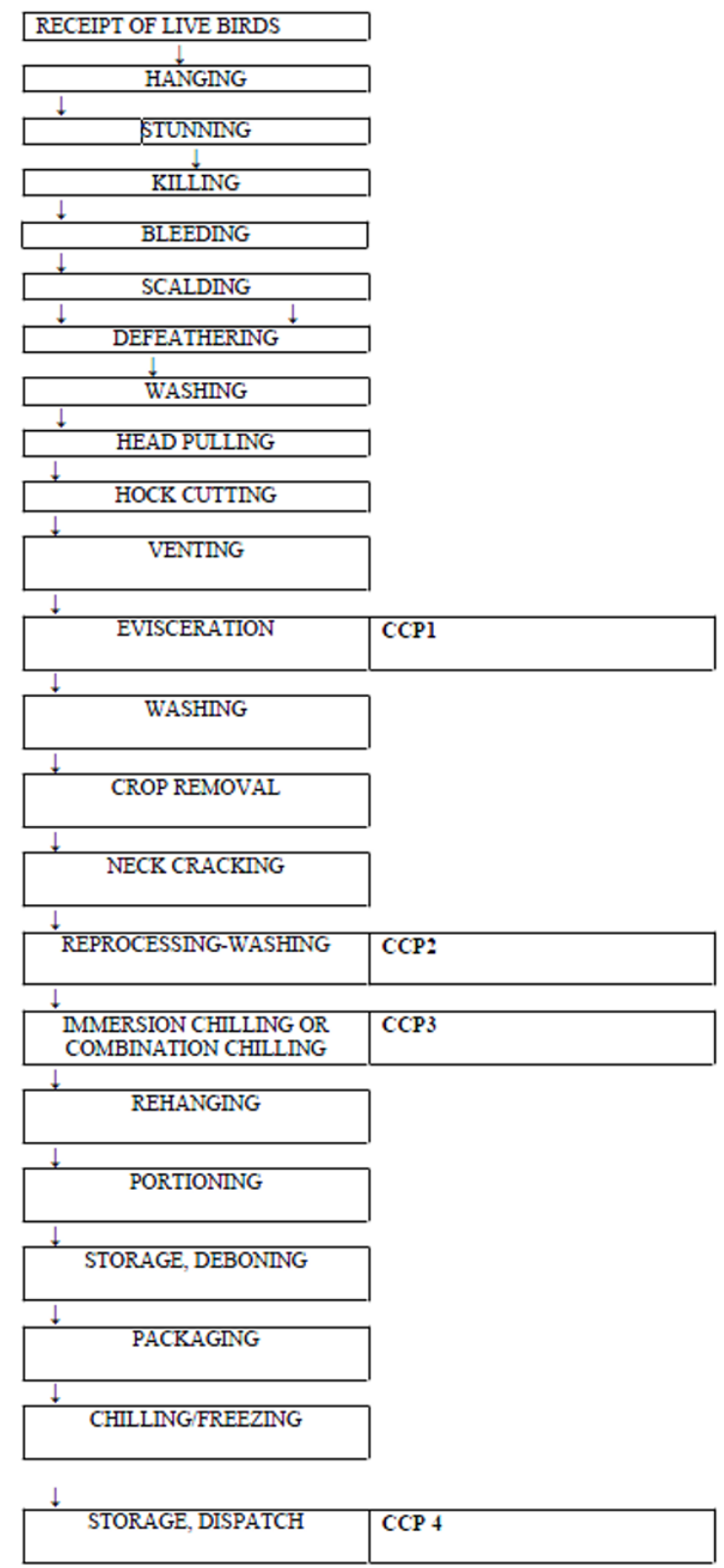

Figure 1. Flow Diagram of Slaughter and Dressing of Chicken Broilers (Adapted from MAF New Zealand, 2000) 


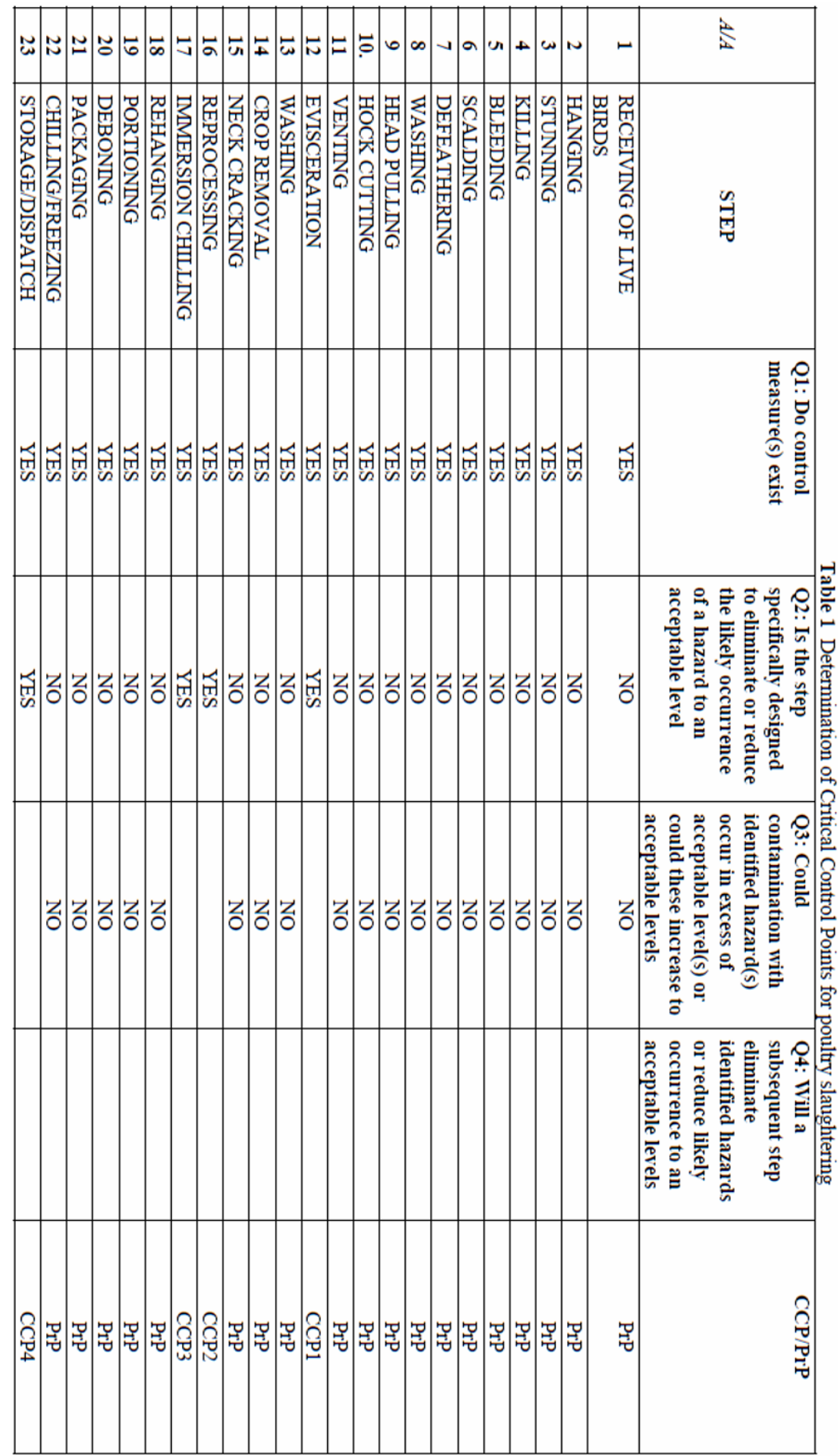




\begin{tabular}{|c|c|c|c|c|}
\hline 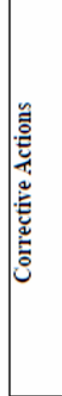 & 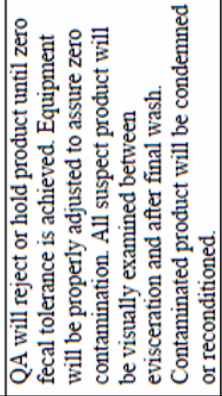 & 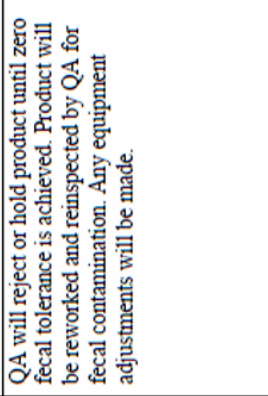 & 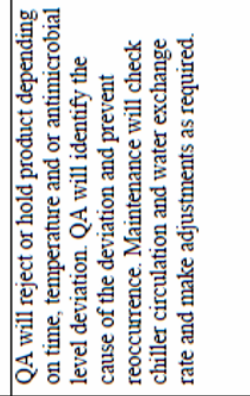 & 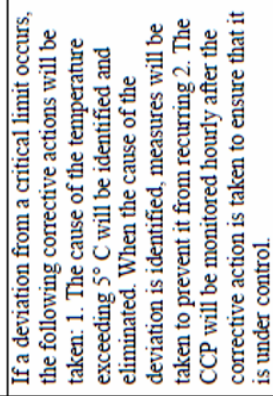 \\
\hline & 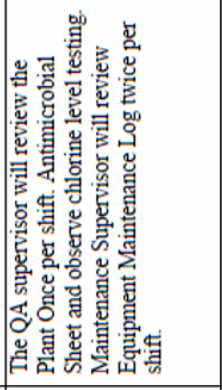 & 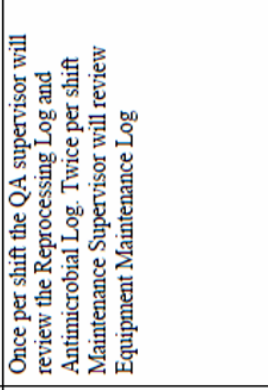 & 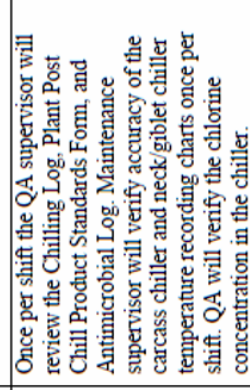 & 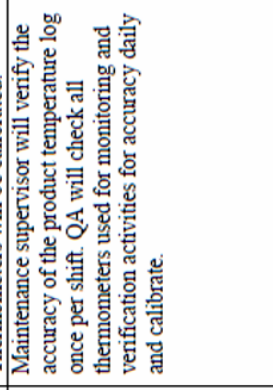 \\
\hline & 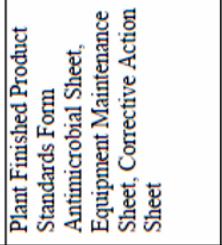 & 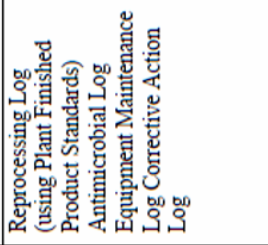 & 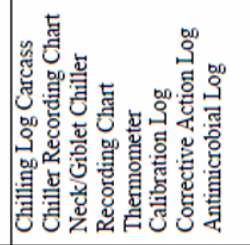 & 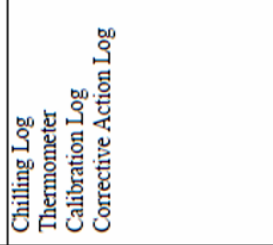 \\
\hline & 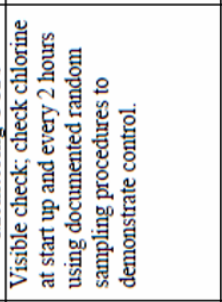 & 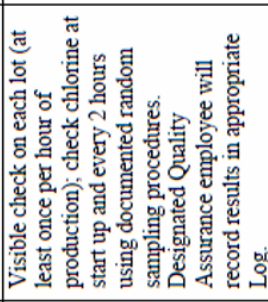 & 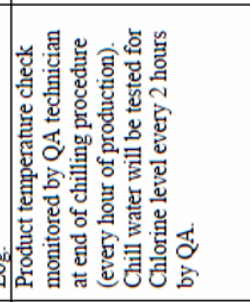 &  \\
\hline & 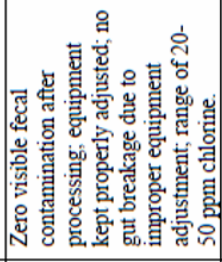 & 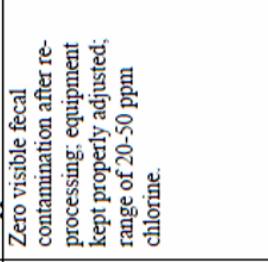 & 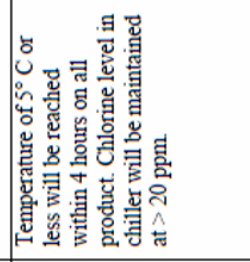 &  \\
\hline 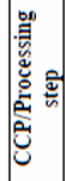 & & 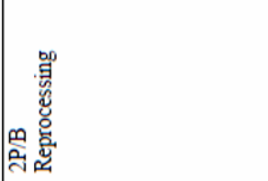 & 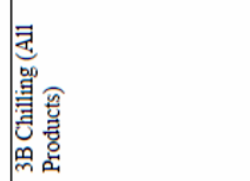 & 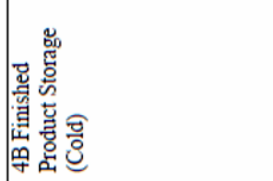 \\
\hline
\end{tabular}




\begin{tabular}{|c|c|c|c|c|c|}
\hline 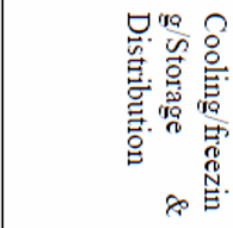 & 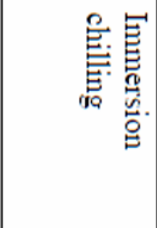 & 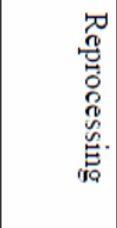 & 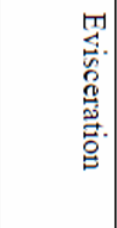 & 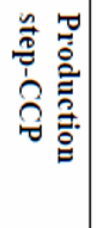 & \multirow[b]{12}{*}{ 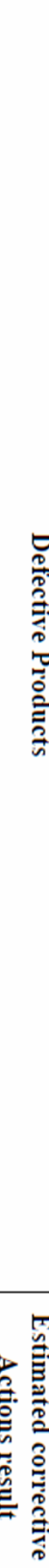 } \\
\hline 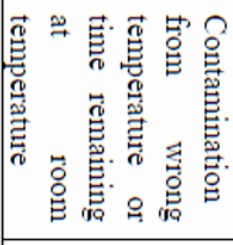 & & 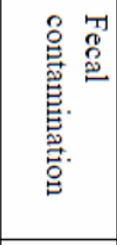 & 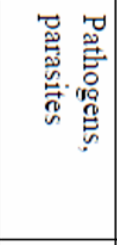 & 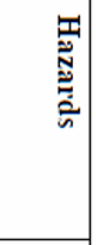 & \\
\hline 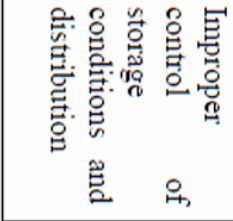 & 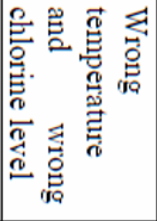 & 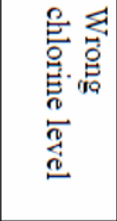 & 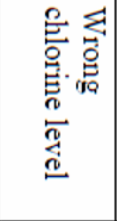 & 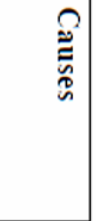 & \\
\hline$\checkmark$ & $\infty$ & 0 & 0 & $\sim$ & \\
\hline in & $a$ & $\checkmark$ & 0 & 0 & \\
\hline$a$ & un & $\triangle$ & 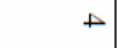 & $\bullet$ & \\
\hline$\stackrel{ }{\circ}$ & $\begin{array}{l}n \\
+ \\
0 \\
*\end{array}$ & 芯 & $\begin{array}{l}w \\
\mathbb{1} \\
\pm \\
*\end{array}$ & 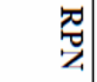 & \\
\hline 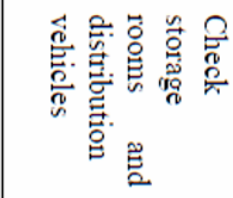 & 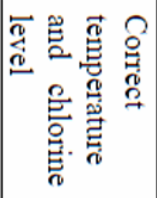 & 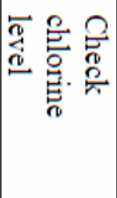 & 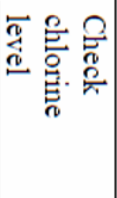 & 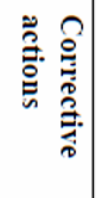 & \\
\hline$\checkmark$ & $\infty$ & 0 & $\infty$ & $\infty$ & \\
\hline$N$ & $N$ & $N$ & $\omega$ & 0 & \\
\hline N & $N$ & $N$ & $w$ & $\ominus$ & \\
\hline N & $\mathbf{N}$ & a & $\mathbf{N}$ & 疍 & \\
\hline
\end{tabular}




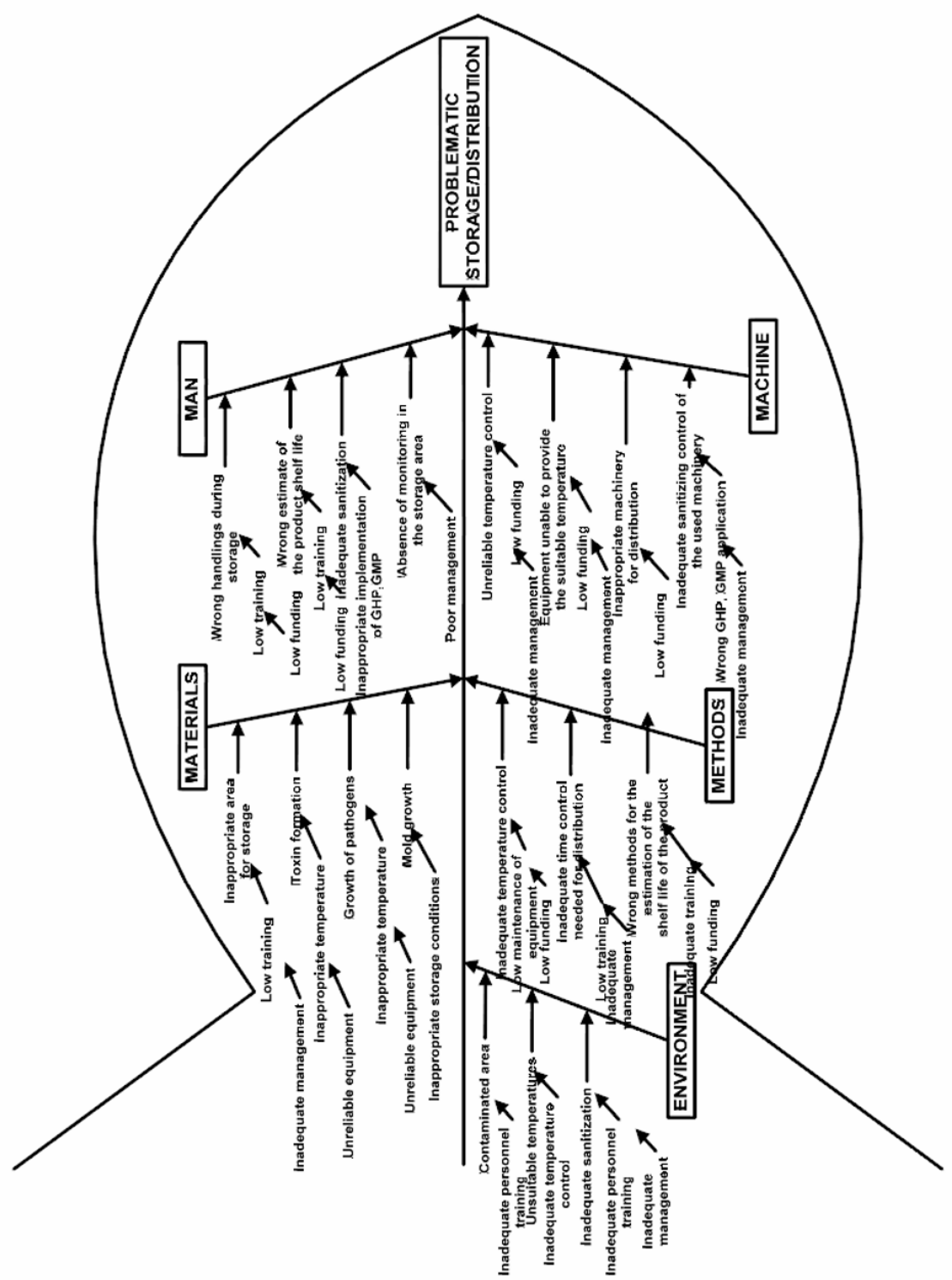

Figure 2. Application of the Cause-and-Effect diagram (Ishikawa diagram) to ready to eat vegetables (CCP problematic storage/distribution of poultry). 


\section{REFERENCES}

Bailey, J.S., Thomson, J.E. and Cox, N.A. (1987). Chapter 5: contamination of poultry during processing. In: "The Microbiology of poultry meat products".

Baumgart, J. (1993). Lebensmitteluberwachung und Qualitatssicherung. Fleischwirtsch, 73(4), 392-396.

Bolder, N.M. (1998). Chapter 5: The microbiology of the slaughter and processing of poultry. In: "The Microbiology of meat and poultry". Davies, A., and Board, R. (EDS.). Blackie Academic and Professional, London.

Goodfellow, S.J. (1995). Implementation of the HACCP program by meat and poultry slaughterers. In: "HACCP in meat, poultry and fish processing", eds. A.M. Pearson and T.R. Dutson, Blackie Academic and Professional, London, pp. 58-71.

Hinton, M.H., Allen, V.M., Tinker, D.B., Gibson, C. and Wathes, C.M. (1996). The dispersal of bacteria during the defeathering of poultry. In: "Factors affecting the microbial quality of meat". 2. Slaugher and dressing. Hinton, M.H., and Rowlings, C. (eds.). University of Bristol Press, Bristol, U.K. pp. 113-121.

Humphrey T. (2004). Control of Campylobacter spp. in the food chain: a far from simple task. Culture, 25, 6-9.

Izat, A.L., Colberg, M., Driggers, C.D. and Thomas, R.A. (1989). Effects of sampling method and feed withdrawal period o $\mathrm{n}$ recovery of microorganisms from poultry carcasses. Journal of Food Protection, 52, 480-483.

Kim, J.W., Slavik, M.F., Griffis, C.L. and Walker, J.T. (1993). Attachment of Salmonella typhimurium to skins of chicken scalded at various temperatures. Journal of Food Protection, 56, 661-665, 671.

Lillard, H.S. (1990). The impact of commercial processing procedures on the bacterial contamination and cross-contamination of broiler carcasses. Journal of Food Protection, 53, 202-204.

Mackey, B.M. and Roberts, T.A. (1993). Verbesserung der Schlachthygiene durch HACCP und Uberwachung. Fleischwirtsch, 73(1), 34-43.

MAF Food Assurance Authority. (2000). Generic HACCP plan for slaughter, dressing, portioning and deboning of chicken (broilers).

NACMSF (National Advisory Committee on Microbiological criteria for foods) (1997). Generic HACCP application in broiler slaughter and processing. Journal of Food Protection, 60, 579-604.

Sandrou, D.K. and Arvanitoyannis, I.S. (1999). Implementation of Hazard Analysis Critical Control Point in the meat and poultry industry. Food Reviews International, 15(3), 265-308.

Sumner, J., Raven, G. and Givney, R. (2004). Have changes to meat and poultry food safety regulation in Australia affected the prevalence of Salmonella or of salmonellosis? International Journal of Food Microbiology, 92, 199- 205.

Sarwari, A., Magder, S., Levine, P., McNamara, A., Knower, S., Armstrong, G., Etzel, R., Hollingsworth, J., Morris, J., 2001. Serovar distribution of Salmonella isolates from food animals after slaughter differs from that of isolates found in humans. Journal of Infectious Diseases 183: 1295-1298.

Schlosser, W., Hogue, A., Ebel, E., Rose, B., Umholtz, R., Ferris, K., James, W., 2000. Analysis of Salmonella serovars from selected carcasses and raw ground product sampled prior to implementation of the pathogen reduction: hazard analysis and critical control point final rule in the US. International Journal of Food Microbiology 58: 107-111.

Stals, P. (1996). Slaughter and dressing of poultry. In: "Factors affecting the microbial quality of meat. 2. Slaughter and dressing". Hinton, M.H., and Rowlings, C. (eds.). University of Bristol Press, Bristol, U.K. pp. 99-105. 
Tinker, D.B., Gibson, C., Hinton, M.H., Wathes, C.M. and Allen, V.M. (1996). Defeatheringengineering developments. In: "Factors affecting the microbial quality of meat. 2. Slaughter and dressing". Hinton, M.H., and Rowlings, C. (eds.). University of Bristol Press, Bristol, U.K. pp. 123-131.

Tompkin, R.B. (1994). HACCP in meat and poultry industry. Food Control, 5(3), 153-161.

Untermann, F. (1993). Hygienanforderungen an die Verarbeitung von Fleisch. Fleischwirtsch, 73(4), 389-392.

Yang, H., Li, Y. and Johnson, M.G. (2001). Survival and Death of Salmonella Typhimurium and Campylobacter jejuni in Processing Water and on Chicken Skin during Poultry Scalding and Chilling. Journal of Food Protection, 64, 770-776 